Synopsis: Decommissioning in the

North Sea presents some major technical and engineering challenges. It also brings significant opportunities for

industry learning and academic research. This paper forms part of an on-going longitudinal study that aims

to determine engineering and management best practices for costeffective and safe decommissioning of redundant North Sea assets.

Paper Title: "Costing and Technological Challenges of Offshore Oil and Gas Decommissioning in the UK North Sea"

Accepted for publication - 2017

Citation: Ahiaga-Dagbui, DD; Love PED; Whyte A; Boateng P. (2017) ASCE Journal of Engineering and Construction Management, forthcoming, $\mathrm{xxx}$ 
4

5

6

7

8

9

10

11

12

13

14

15

28

\title{
Costing and Technological Challenges of Offshore Oil and Gas Decommissioning in the UK North Sea
}

\author{
Dominic D Ahiaga-Dagbui \\ ${ }^{1}$ PhD., Lecturer, Scott Sutherland School of Architecture and Built Environment, Robert \\ Gordon University, Aberdeen, AB10 7QB, Scotland, United Kingdom
}

Email: d.d.ahiaga-dagbui@rgu.ac.uk

(Corresponding Author)

Peter E.D Love

Sc.D., Ph.D., John Curtin Distinguished Professor, Dept. of Civil Engineering, GPO Box U1987, Perth, WA 6845, Perth, Australia, Email: p.love@ curtin.edu.au

Andrew Whyte

Ph.D., Head of Department, Dept. of Civil Engineering, GPO Box U1987, Perth, WA 6845, Perth, Australia, Email: a.whyte@ curtin.edu.au

\section{Prince Boateng}

PhD., Lecturer, The School of Built and Natural Environment, Koforidua Technical

University, Ghana. Email: p.boatengh@yahoo.com 
30 Abstract: A significant number of offshore oil and gas installations in the United Kingdom's

31 (UK) North Sea have either exceeded or are approaching the end of their designed economic

32 life. Operators and contractors are confronted with an array of challenges, which hinder the

33 cost effective and safe completion of decommissioning projects. The costing and technological

34 challenges that confront the oil and gas industry are identified using a series of semi-structured

35 interviews. One of the most prominent challenges identified was the inability to reliably

36 estimate the volume and cost of work to be undertaken. This is exacerbated by a supply chain

37 with limited capacity and experience in executing decommissioning projects in this fledgling

38 sector in the oil and gas industry. As a result of the analysis that is undertaken, it is

39 recommended that an industry-wide decommissioning forum be established to facilitate the

40 sharing of experience and knowledge, particularly with regard to cost information so that operators and contractors can ameliorate the planning and management of the

42 decommissioning process.

43

44 Keywords: Decommissioning, cost management, offshore, North Sea, engineering 45 management, oil and gas 
49 Oil and gas production from the United Kingdom Continental Shelf (UKCS) in the North Sea provides a significant source of revenue for the Government. Since the 1970s, the industry has paid more than $£ 300$ billion (US $\$ 440$ billion) in production tax alone to the UK Treasury (Oil \& Gas UK, 2015b). The industry contributed $£ 6.5$ billion and $£ 5$ billion (US\$9.5 and $\$ 7.3$ million) in production taxes only in 2012/13 and 2013/14 fiscal years, respectively (Oil \& Gas UK, 2013, 2014a). It also accounts for about half of UK's energy demand (DECC, 2014).

There are currently over 600 offshore oil and gas installations in the North Sea, 470 of which are in UK waters (OSPAR, 2015). These comprise of topsides, steel platforms, concrete gravity based sub-structures, subsea and floating equipment, in addition to more than $10,000 \mathrm{~km}$ of pipelines, approximately 5,000 wells and their drill cuttings as well as 15 onshore terminals (DECC, 2014; OSPAR, 2015). After 40 years of oil and gas production, however, a significant number of offshore installations have either exceeded or are approaching the end-of-their designed economic life span and have to be decommissioned to meet the stringent regulatory framework of operating in the North Sea. Oil and Gas UK (2015a), the industry representative body, conservatively estimates the cost of decommissioning to be between $£ 41$ to 46 billion (US\$63 to 70 billion), but recent estimates suggest that the total bill could be as high as $£ 70$ billion (US\$107 billion) by the year 2040 (Genesis and DECC, 2015).

66

Decommissioning, the final stage in the life-cycle of an oil and gas project, is the process of planning, seeking government approval and implementing the abandoning or removal of the structure when it is no longer required. The decommissioning programme is usually a long, cost-intensive and convoluted chain of activities that involves several stakeholders and many considerations in relation to the environment, health and safety, social, economic and technical 
completed within 10 years (Wilkinson et al., 2016). The program has involved eight years of engineering studies, expert input, scientific assessments, including extensive consultations with more than 200 non-governmental organisations, academia and local communities.

77 The exact timing for when the decommissioning of an offshore structure could occur is not 78 often resolves around a number of factors, which include:

- the age of the installation and associated infrastructure;

- $\quad$ current regulations regarding exploration and production;

- the price of oil, market volatility and whether is economically viable to continue operating the asset;

- whether there could be any technological advances to extend the life of the asset for more efficient oil and gas recovery particularly in mature fields; and

- $\quad$ the fundamental question of whether there is still any oil and gas reserve to exploit at all.

87 The notion of decommissioning in the oil and gas sector is in its infancy, particularly in the

88 North Sea, and therefore operators and contractors are facing new engineering, environmental, organizational and health and safety challenges when removing redundant structures. Fowler et al. (2014) propose a multi-criteria decision framework for evaluating and comparing alternative decommissioning options using key selection criteria such as environmental issues, financial case, socioeconomic justification as well as health and safety considerations. Ekins et al. (2006) carried out a material and energy flow analysis for different decommissioning scenarios for the different elements of an offshore oil and gas structure. Hamzah (2003) explored the international law and practice on the decommissioning of offshore installations and examines the various global and regional instruments used in regulating decommissioning.

97 Like Hamzah (2003), Parente et al (2006) explore the decommissioning problem from a legal 
perspective - they analyze the ex-ante deductibility of decommissioning costs as they constitute an ex-post expense as well as the possible challenges of perpetual liability when ownership of the offshore asset has been transferred to a new licensee under current regulations (refer to Section 16 of The Guidance Notes to Decommissioning of Offshore Oil and Gas Installations (DECC, 2011)). Kaiser and Liu (2014) also used the work decomposition algorithms developed by ProServ Offshore to estimate cost for well plugging and abandonment, pipeline abandonment, umbilical and flowline removal, and platform removal for the 53 deepwater fixed platforms and compliant towers in the Gulf of Mexico.

Yet, a detailed review of the extant engineering and management literature reveals that there is a paucity of research that has examined the complexities with the management and planning processes associated with decommissioning offshore oil and gas facilities. The decommissioning research that has been undertaken has tended to focus on environmental impacts and the feasibility of using platforms to facilitate and stimulate the well-being of marine ecosystems (eg Ekins et al., 2006; Bernstein et al., 2010). Indeed, rather than dealing with decommissioning directly, industry seems content to re-channel its energies away from the issue at hand, towards developing alternative exploitation solutions by increasingly targeting efforts into the development of Floating-Production-Storage-and-Offloading (FPSO) systems where some 160 such vessels worldwide are in place to develop deep-water resources (Rini et al., 2016a). It would appear that the sector's fixation upon exploitation has overlooked the importance of attending to aging fixed-rigs and is focused on fresh-starts that are afforded by FPSOs opportunities and their related life-cycles (Rini et al., 2016b). Building on the limited research undertaken into decommissioning, this paper explores the costing and technological challenges that operators and contractors are confronted with during the decommissioning process. 


\section{Offshore Oil and Gas in the North Sea}

124 The UK oil and gas industry is being confronted with significant challenges, which have been

125 exacerbated by low oil prices, high cost of operation, uneconomic fields, and high taxes. After 126 oil prices fluctuated between US\$100 to 115 per barrel from 2011 to 2013, Brent prices 127 collapsed in 2014, reaching lows of below US\$30 per barrel by January 2016 (Oil \& Gas UK, 128 2015a; DecomWorld, 2016). According to the most recent Activity Survey by Oil and Gas UK 129 (2015a), the total operating expenditure in the UKCS rose by $8 \%$ between 2013 and 2014 from $£ 8.9$ to $£ 9.6$ billion. This was at the back of a $10 \%$ and $16 \%$ increase over the previous two

131 years, respectively. The sector also generated a negative cash flow for the second consecutive 132 year in 2014 . The 2014 deficit in cash flow was $-£ 5.3$ billion compared to $-£ 0.4$ billion in 2013.

133 To put these figures in context, the last time the industry experienced a negative cash flow was 40 years ago when the most of the large UKCS assets were only being developed (Oil \& Gas UK, 2015a).

137 The UK Revenues and Customs (2016) stated that "low oil prices in 2015/16 combined with continuing high levels of investment and increasing amounts of decommissioning expenditure have resulted in government revenues declining to $-£ 24 \mathrm{~m} "$, their lowest levels since records began in 1968. The comparable figure for 2014 to 2015 was a positive balance of $£ 2.15$ billion.

141 The volatility in oil prices and the potential of them to remain under US\$40 per barrel has

142 resulted in operators having to address the following question: Extend production of late life 143 assets by seeking to transfer asset-ownership and its associated risks or, initiate 144 decommissioning and well abandonment? In a recent survey by DecomWorld (2016), 73\% of 145 the respondents from the North Sea industry agreed that US oil prices below US $\$ 40$ will 146 accelerate decommissioning activities as assets simply become uneconomical to operate and 147 maintain. 
In 2014, a total of $£ 1$ billion had been expended on decommission activities in in the North Sea

149 (Oil \& Gas UK, 2015a). This represents a significant increase from the $£ 470$ million that was spent in 2013 (Oil \& Gas UK, 2014b). This figure is, however, set to rise further over the next

151 five years and could surpass $£ 2$ billion in 2018 (Oil and Gas Authority, (2015a). Feedback

152 provided by operators in the UKCS has suggested that there will be significant reduction in new investments due to the prevailing economic climate; it has been estimated that only $£ 3.5$ billion will be invested on capital projects between 2015 and 2018 (Oil \& Gas UK, 2015a).

\section{The North Sea Regulatory Framework}

157 A legal and regulatory framework governing the international, regional and national concerns associated with the decommissioning process has been established in the UK (Löfstedt and Renn, 1997; Bennie, 1998). In accordance with existing regulations, a majority of installations have to be wholly removed and dismantled and disposed onshore. The Oslo-Paris Convention (OSPAR) is the current legal instrument guiding international co-operation on the protection of the marine environment in the North-East Atlantic. Until 1995, the OSPAR Convention under certain circumstances permitted the disposal at sea of parts or all of offshore installations. This, however, changed after the famous Brent Spar controversies that saw Shell UK reverse its plans for deep-sea disposal of the facility following protests led by the environmental activist, Greenpeace (Löfstedt and Renn, 1997; Bennie, 1998). As a consequence, OSPAR

167 Decision 98/3, which covers the disposal of disused offshore installations and came into force 168 in February 1999. It states that:

170 1. The dumping, and the leaving wholly or partly in place, of disused offshore installations within the maritime area is prohibited. 
172 2. Reuse, recycling or final disposal on land will generally be the preferred option for the decommissioning of offshore installations in the maritime area.

174

175 It follows that all topsides of structures or jackets weighing less than 10,000 tons must be 176 completely removed for reuse, recycle or disposal on land (OSPAR, 1999). Moreover, Decision

$17798 / 3$ recognizes that the decommissioning of some large installations situated in marine ecosystems may pose both technological and safety challenges, as well as expose the environment to increased risks of contamination. For large concrete substructures, footings of jackets weighing more than 10,000 tons or concrete anchor bases and structures with significant damaged, operators may apply for derogation; that is, to leave some structures in situ. In these circumstances, it must be demonstrated that there are significant reasons why an alternative disposal method is preferable to re-use or recycling or final disposal on land (OSPAR, 1999). The Department of Energy and Climate Change (DECC) provides the UK industry with guidance to assist operators comply with the requirements of the under the auspices of the Petroleum Act 1998. This guidance addresses the process for a derogation application under OSPAR 98/3. Only British Petroleum's North West Hutton and the three Frigg platforms of Total E\&P have so far been granted derogation in the UK North Sea (DECC, 2014).

The OSPAR Decision 98/3 recognizes the difficulties involve when removing large steel

191 jackets weighing more than 10,000 tones and their footings that were installed before 1999. As

192 a result a provision is made for derogation from the requirement of total removal for such jackets. Though, there is a belief that the jackets can be removed entirely, flexibility can be granted only if a detailed comparative assessment of options and consultation with stakeholders demonstrates that there is no better alternative disposal method. An overview of decommissioning alternatives is presented in Figure 1. 


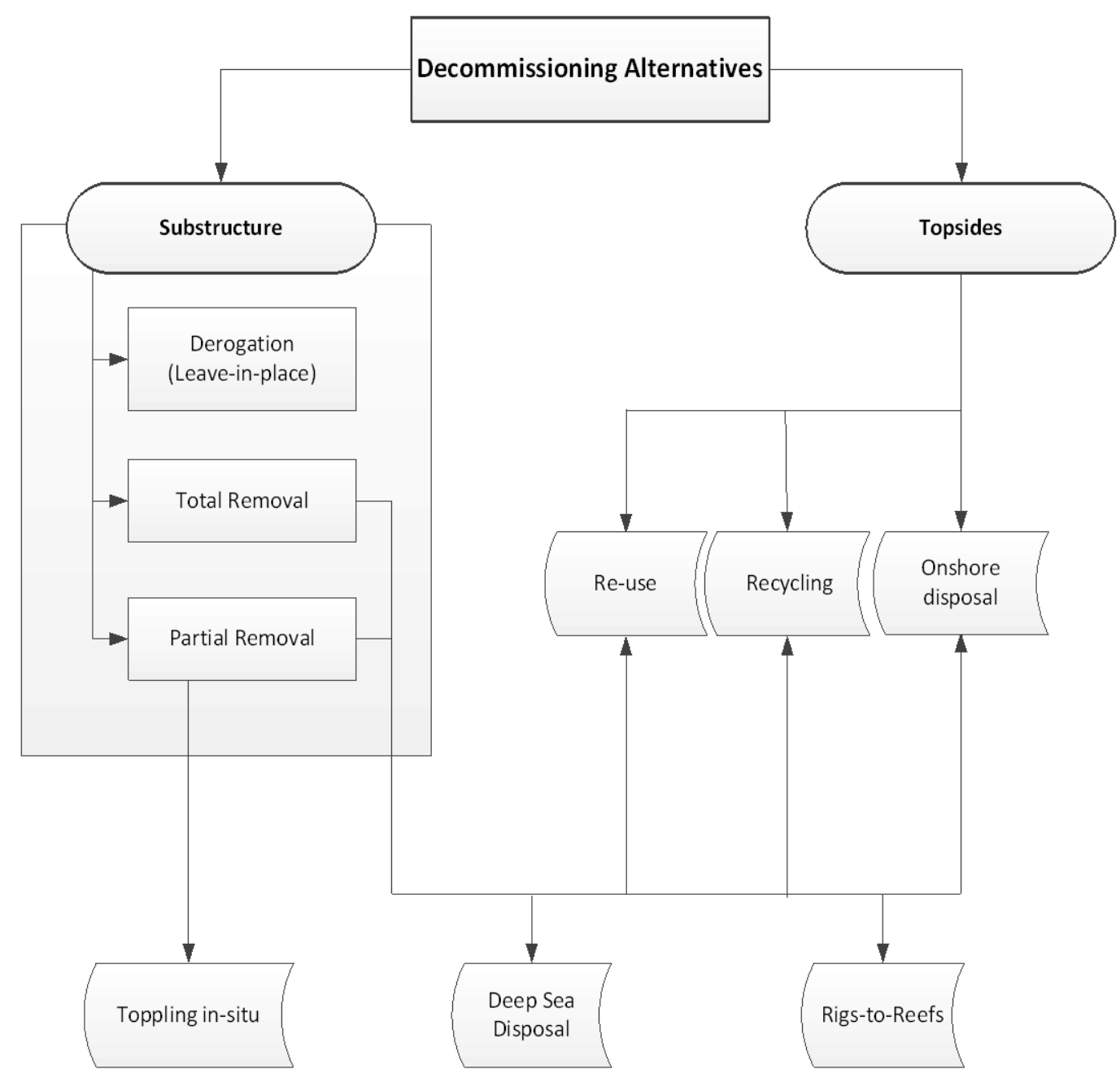

198 Figure 1 can be developed and extended by including life-cycle assessments (LCA) and life199 cycle cost analyses (LCCA) by examining the full range of alternative options for an end-of200 life review (Whyte and Laing, 2012). The full range of disposal options for each sub-element 201 material requires empirical comparison towards recommendations for best practicable 202 environmental option(s) disposal of an offshore asset's constituent material parts.

204 Disposal options for a decommissioned asset's waste-arising sub-categories (such as concrete, 205 plastic, ferrous metal, non-ferrous metal, and cable) can be compared. Table 1 is adapted from 206 previous on-shore construction and demolition (C\&D) waste research (Whyte et al., 2005; 207 Whyte and Laing, 2012) and provide summaries of: the waste sub-category, recycling process 208 and material disposal options; an Ecopoint (Dickie and Howard, 2000) environmental-impact 
210 options as well as a ranking system to guide choice of disposal. A ranking of one is deemed

211 the most desirable waste disposal option and a ranking of four or five deemed the least 212 desirable.

214 According to the Petroleum Act 1998, there are three main post-decommission requirements:

215

216 1. Periodic monitoring of any remains of an installations specified in the decommissioning 217 programme submitted to the DECC, with maintenance or some form of remedial action 218 wherever necessary.

219 2. Information confirming the existence of any remains of an installation will be passed onto mariners and appropriate hydrographical services and will be marked on nautical charts.

$2213 . \quad$ Perpetual liability remains with the owner of the asset. 
Table 1: Constituent Material Disposal Comparison

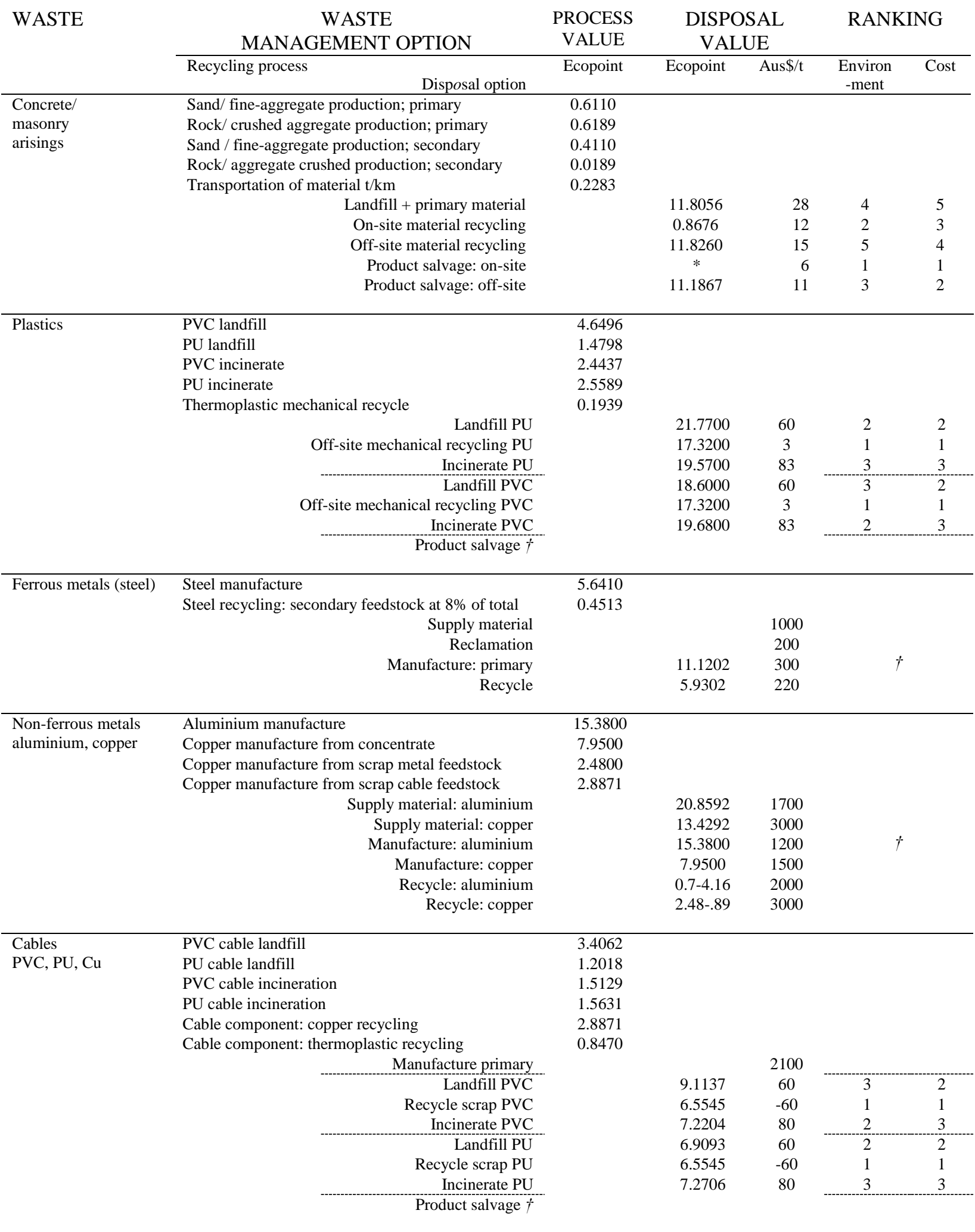

+ established re-use/ recycling route: intrinsic value

Data above represent on-shore values, with off-shore activities as an essential extra requirement for future work 
228 Policies of complete removal are based upon the assumption that 'leaving the seabed as you found

229 it' represents the most environmentally-sound decommissioning option. However, there is 230 widespread evidence that has demonstrated that during the production life of an oil and gas 231 structure, remaining structures are capable of developing rich and diverse marine communities 232 (eg. Bell and Smith, 1999; Love et al., 2006; Macreadie et al., 2011, 2012). In the Gulf of Mexico, 233 for example, platforms support populations of red snapper (Lutjanus campechanus) (Gallaway et 234 al., 2009) and in Southern California rockfish (Sebastes paucispinis) (Love et al., 2006). 235 According to Fowler et al. (2014) the removal of oil and gas structures may not represent best 236 environment practice, with some countries recognizing that leaving obsolete structures in place as 237 artificial reefs (rigs-to-reefs) is a more appropriate action. Notably, however, platforms that are converted to artificial reefs could be subject to 'fishing pressure', which would reduce the fish populations remaining after decommissioning (Bernstein et al., 2010). While authorities could place a restriction on fishing, they need to be mindful of existing legislation and any amendments

241 that may be required to it in order to ensure an ecosystem remains in equilibrium (Bernstein et al., 242 2010).

244 Not all of the alternative uses or disposal options are equally viable technically, economically or 245 politically; impacts on the benthic communities, birds, marine mammals, water quality, 246 commercial/recreational fishermen, commercial shipping and the like will naturally vary 247 (Bernstein et al., 2010; Fowler et al., 2014). Needless to say, whatever option is adopted, there 248 remain engineering and management challenges that need to be explored to ensure the decommission process is undertaken cost effectively, safely and environmentally friendly. 
251 This research forms part of a longitudinal study that aims to determine engineering and

252 management best practice for the cost-effective planning and execution of decommissioning 253 projects faced by a fledgling decommissioning sector. Due to the current limited research that

254 has been undertaken in this field of study, a qualitative approach was undertaken to obtain an understanding of issues that oil and gas professionals faced.

\section{Data Collection}

Critical case sampling (Patton, 2001) is particularly useful in explorative qualitative research where small number of cases or sample, was used to explore the current challenges to decommissioning in the North Sea. Whilst critical case sampling does not allow for statistical generalizations, it can be very useful for making logical generalizations the rich evidence gathered regarding a phenomenon. Six key questions were identified through a review industry and government reports on the scale and nature of decommissioning. Pilot interviews with three oil and gas industry professionals with experience in North Sea decommissioning suggested that these initial questions made a suitable research instrument.

Respondents were asked a mixed set of open-ended questions such as:

- What are some of the major challenges faced at planning stage of decommissioning projects you were involved in?

- Can you discuss the main challenges you face at the execution stage of decommissioning projects you were involved in? projects? 
- Are there any challenges associated with reliably estimating the costs of decommissioning projects?

- What are some of the key challenges related to well Well Plug and Abandonment (P\&A) activities?

Interviewees from various functional areas and organizations that were actively involved in planning or execution of decommissioning projects in the North Sea were selected using purposive sampling. This approach was employed as decommissioning is still in its infancy in the North Sea and globally, therefore the need to target the relatively small number of organizations and industry workers who are already involved in this area.

A total of 15 semi-structured interviews were conducted after the completion of the pilot study with a variety of personnel across seven operator organizations and five contractors and consulting companies. The interviewees included decommissioning managers, project managers, late-life asset managers, business development manager, decommissioning team Members, operations coordinator, plug \& abandonment engineer and a special projects lead. These interviewees had between two to 11 years of experience in either the planning or execution of decommissioning in the North Sea.

In addition to the questions raised in the interview, the interviewer used their judgment to improvise and ask follow-up questions where necessary to explore a particular answer in further detail. Where permission was granted, the interviews were recorded and digitally transcribed. Notes were also taken by the researcher to supplement interview data that was obtained. The interviews were mainly conducted face-to-face, with the exception of two that were conducted over the phone due to scheduling constraints. The interviews lasted between 

researchers then constructed thematic categories of challenges to decommissioning that was evident through the interview.

\section{Findings and Discussion}

305 Many of the North Sea's near-future oil and gas decommissioning projects will be the first to 306 be undertaken by their respective operators. The decommissioning program is usually a long, cost-intensive and perceived by some to be a convoluted chain of activities that involves an array of stakeholders such as the operators, contractors supply chain, government departments, environmental groups and other users of the sea. As part of the decommissioning programme submitted to the Department of Energy and Climate Change (DECC) in the UK, Operators are required to conduct a Comparative Assessment (CA) of alternative scenarios of removal of offshore installation to demonstrate that a fully evaluated and justified process has been undertaken to support whichever option is finally chosen (DECC, 2011). DECC stipulates that

314 the assessment be carried out under five main criteria:

1. Economic - total cost of the proposed option

2. Technology - relates to technical feasibility, ease of recovery and use of proven technology and equipment

3. Safety - risks to project personnel offshore and onshore as well as any residual safety risks to users of the sea

4. Environmental - relates to impact on the environment (spillage, contamination etc.), $\mathrm{CO}_{2}$ emissions and total energy usage

5. Societal - socio-economic impact of the decommissioning on communities and amenities. 
325 While there are significant challenges in all of the areas identified above, the scope of this

326 paper covers only the economic (cost challenges) and technological challenges that emerged

327 from the interviews.

328

329 Costing Challenges

330 Cost overruns during the decommissioning process were repeatedly identified as being a

331 pervasive problem for operators and contractors. For example, an interviewee stated:

332

333

'Typically the estimates are class 4 or 5 [of the American Association of Cost Estimating benchmarks]. They are very conceptual and so the actual cost could be \pm 100 or $200 \%$...'

335

336 Producing accurate cost estimates at the planning stage of a project is crucial for their

337 successful delivery, as the estimates produced may influence an operator's decision regarding

338 whether to actually proceed with the decommissioning process or extend the life of the asset.

339 The estimates that are produced also influence the method and process of decommissioning

340 that can be adopted as well as the type of contracts and contractors to use (e.g., single lift,

341 reverse installation or small piece implementation). Despite the great importance of cost

342 estimation, such projects are subjected to heightened levels of uncertainty, complexity due a

343 lack of information such as an asset's structural/well integrity, availability of removal vessels

344 (i.e. with lift capacities in excess of 500 tonnes are often required), supply of a workforce with

345 the appropriate engineering and operational skills, re-use and resale, and port capabilities. A

346 lack of information led a Life Asset Manager to state: 
'It is usually easy for us to go into our cost database for most of the other works we undertake and build estimates from there. This is not the case for the decommissioning work because we just haven't done this before. It's a whole new territory for us.'

350

351 Due to such levels of uncertainty and an absence of empirical cost data for producing reliable 352 estimates, a significant number of decommission projects overrun their initial budgets. The

353 Decommissioning Manager of one of the large North Sea Operators thus stated: 'Historically, the final cost of decommission projects have been $40 \%$ more than the estimated cost. So obviously the industry is not particularly good at this.'

Having a limited portfolio and planning experience was also identified as issue that contributed to the problem of overruns being experience with decommissioning projects. Several of the interviewees suggested that the use of incentivized contracts with a pain/gain mechanism in place instead of the use of day-rates, which are typically used, had the potential to reduce decommissioning costs. While this was a common sentiment amongst operators, contractors generally felt this would not necessarily assist in reducing costs as targets may have to be readjusted in light of more reliable project data or would have to resort to variation orders (change orders) or litigation to recoup costs.

367 Collaboration has come to the fore in relation to decommissioning, as the oil and gas industry 368 has begun to realize companies need to work closer together to obtain cost efficiencies and 369 improve productivity. The actual nature of collaboration presents a dilemma for the industry, particularly with regard to developing new decommissioning technology and the ownership of 
intellectual property. Arising from the discourse that materialized with interviewees there appeared to be unwavering support to engage in collaborative contracting so as to stimulate much needed technological and process innovation.

It was revealed from the interviews that there was a proclivity for larger companies undertaking decommissioning projects to be constrained by their corporate policies and administrative departments that were responsible for legal, environment, procurement, health and safety issues. As such departments compete for their influence in a project, the potential to hinder operating efficiency increases and this can increase costs. Acknowledging the burgeoning influence of these departments in decommissioning projects, several operators suggested that they often tried to circumvent their direct involvement by creating a temporary administrative unit to deal with such issues.

\section{Complexity, Uncertainty and Experience}

As noted above, the complexity and uncertainty of the decommissioning process plays a crucial role in producing a reliable cost estimate. Simon (1993) describes a complex system as one in which the behavior of the 'whole' is difficult to deduce from understanding the individual parts; that is, while it may be easy to know the effects that impacted upon the project and its outturns, it can be difficult to understand intuitively how the latter came from the former. This may be due to a project's complexity producing a totality of effect beyond the sum of the results that would be expected from individual causes. Hamilton (1997) outlines two important properties of systems thinking that would be useful in cost overrun research: (1) every part of a system has properties that it loses when separated from the system; and (2) every system has some essential properties that none of its parts do. Thus, when a system is taken apart, it loses 
its essential properties (this concept can be traced back to Von Bertalanffy, 1956).

397 The usual approach for costing for offshore projects is to break the entire project down into 398 small manageable parts or packages using a work breakdown structure. Likely costs are then 399 associated with each of these parts and their total cost aggregated with a mark-up for risk and 400 uncertainty. The approach is largely deterministic in nature and does not accommodate the 401 probabilistic nature of outcomes in complex systems. Remington and Pollack (2007) describe four different types of complexity:

404 1. Structural complexity: The complexity that stems from the difficulty in managing and 405 keeping track of the huge number of different dependant and interdependent tasks and activities;

407

2. Technical complexity: Technical or design problems associated with products that have never been produced before, or with techniques that are unknown or untried and for which there are no precedents or experience;

$4103 . \quad$ Directional complexity: Found in projects which are characterised by unshared goals and unclear meanings and hidden agendas. Typical decommissioning projects will have several stakeholders with varying objectives and motivation;

413 4. Temporal complexity: Shifting environmental and strategic directions which are 414 generally outside the direct control of the project team. Usually originates from 415 uncertainty regarding future constraints or expectations of change. Temporal complexity 416 exists on projects that are subjected to unanticipated external impacts significant enough to seriously destabilise the project, such as rapid and unexpected legislative changes or the development of new technologies. 
419 Offshore decommissioning is an emerging sector in the North Sea and exhibits high degrees of 420 the four different complexities identified above. For example, the interview data strongly 421 suggested a high level of technical complexity and uncertainty due to the novelty of 422 decommissioning itself. North Sea decommissioning will be the first global oil and gas 423 decommissioning on such a large magnitude, and therefore there are many aspects of the process and product where there are no notable experiences or precedents to draw on. For example, the cell-content sampling of the sediments at the bottom of the concrete gravity-based structures of the Brent Delta platform, to determine the quantity and composition of these sediments, has never been undertaken anywhere before. The Business Opportunity Manager on Shell's Brent Delta decommissioning project has stated:

"This was not a simple matter of taking off the lids and sucking out some sediment. For a start the cells are located 180 kilometres offshore and the cell tops are 80 metres below the surface of the sea. Their original internal access points are old and complex and their concrete walls are almost a metre thick. And there are only a few weeks in the year when the weather is stable enough to attempt this kind of operation." (Manning, 2015)

435

With complexity, comes uncertainty; the absence of knowledge, the inadequacy of information or unreliability of available information. Uncertainty therefore means that assumptions about performance, schedules, weather, safety and technical complexity may vary significantly in reality. For example, the harsh, challenging working and ever-changing weather conditions of the North Sea means lifting and removal of offshore platforms must be completed during a

441 short period of time in the summer months. The challenge then for a decommissioning planning

442 team is how to develop a reliable cost estimate within an environment of high complexity and 443 uncertainty. 


\section{Portfolio Experience and Benchmarking}

446 Expert knowledge, or professional judgment, which is typically acquired through experience,

447 when used in addition to available historical data can be very useful in reducing uncertainty.

448 However, with a lack of experience being identified within the contracting and consulting 449 community and with only approximately $10 \%$ of the required installations having been 450 decommissioned by different companies (DECC, 2014; Oil \& Gas UK, 2015b) led a Late-Life

451 Asset Manager to make the following comment:

452 'Fundamentally, we still haven't done enough projects to have a good benchmark for costs because there just simply haven't been enough projects in the North Sea. To be frank, the ones we have done haven't really been documented that well in terms of what the costs are, or they're not in the public domain.'

457

There is a heightened tendency towards commercial confidentiality within the oil and gas industry, particularly during the exploration and production phases of a field. This mentality seems to be carried over into the decommissioning phases as well by Operators even though decommissioning is largely a non-profit process and should really be as collaborative as possible to drive down cost. The result of this commercial sensitivity, however, is that there is limited publicly available information that relates to the cost and schedule performance of projects. Benchmark figures are therefore not readily available or reliable enough for forecasting purposes. Current close-out reports submitted to the Department of Energy and Climate Change in the UK (the Government representative body) are generally very limited in information for forward planning for new projects. The information submitted is generally in different formats and provides scant information. The Late-Life Asset Manager further noted: 


\section{$473 \quad$ Scoping Issues}

474 In the North Sea, a high level scope of works is negotiated with the various stakeholders

475 including the Department of Energy and Climate Change, the operator, environmental organizations, and fishermen. An operator typically prefers to undertake as little work as

477 possible to limit their expenditure as decommissioning is a non-profit, end-of-life process, while environmental, pressure-group organizations (e.g. Green Peace) have advocated that installations be completely removed. There is on-going debate about the extent of removal that is required as this often dependent, as noted above, on an array of political, socio-economic and environmental conditions.

The agreed high-level scope of works then has to be distilled into a detailed work plan during the execution stage of the decommissioning process. Thus, the cost of works is inextricably linked to the scope of works. However, it was made explicit during the interviews that the scope of works constant changed due the level of uncertainties that exist during the planning and execution stages of decommissioning. This is particularly the case for subsea infrastructure and plug and abandonment works. Some of the North Sea installations have been in use for almost 40 years and may have changed ownership a from one operator to another over its course of their life. Other structures such as wellhead protection, manifolds and subsea

491 isolation valves are usually designed to accommodate the specific requirements of the field, 492 essentially making them unique. There are no readily tried and tested techniques or thus no one-size-fits-all solution for these structures. Furthermore, the decommissioning of such 
challenges, as they were not fully designed with decommissioning in mind.

496

497 The scoping problem is exacerbated by the limited budget that is available for offshore inspections, engineering surveys and familiarization necessary for the decommissioning team and contractors to effectively plan for actual works to be undertaken. The purpose of the 500 inspections and familiarization are to ascertain the condition of the platform, sample quantity and conditions of materials, verify volume of works, assess removal approach and determine risks associated with the planned works. However, the frequency and number of offshore visits required come with associated costs of accommodation, offshore flights and transit costs, office space, and safety training. Such costs can run into millions of dollars (Little et al (2016). Allocating sufficient resources to achieve effective planning and scoping of decommissioning thus becomes a challenge, especially on unmanned platforms or those that have been abandoned for a number of years prior to actual removal.

A member of the decommissioning team of an operator that had undertaken a large number of P\&A campaigns in the Southern North Sea noted: 'We were always finding new work to be done. You're dealing with a high level of uncertainty in each well. Each well is different. So much would have changed over the 3040 years that you're dealing with a new challenge from well to well. That makes planning and scheduling very frustrating.'

516

517 This uncertainty was evident in the variability of the performance data relating to the P\&A of 51825 wells in 2015 by the company. As at the time of the interviews (May 2016), it took an 
average of 23 days to successfully complete the P\&A of a well. A technical best of 12 days was observed, with one of the wells taking 36 days to complete. Another interviewee added:

521

522

523 'Most of these platforms would have had significant modifications to their structure over their production period to extend the life of the asset or make it structurally safe for continuing operation. The trouble is, in some cases, as-built drawings are not available or up-to-date and thus we have to make a lot of assumptions. This has impact on the cost estimates as well.'

\section{7}

\section{Timing of Decommissioning and Effect on Innovation}

528 Another problem that complicates the planning for decommissioning in the North Sea relates 529 with the timing of Cessation of Production $(\mathrm{CoP})$ at the end of the operation phase of the 530 platform (Figure 2). The offshore oil and gas infrastructure that has been developed over the past 40 years in the North Sea is well documented in the databases of the Oil and Gas Authority (OGA, 2016) and OSPAR (OSPAR, 2016). The scale of the task ahead in terms of decommissioning is generally well understood by the industry. However, what is not clear is

534 how each operator will approach and manage its respective program or when it will actually 535 begin the decommissioning process.

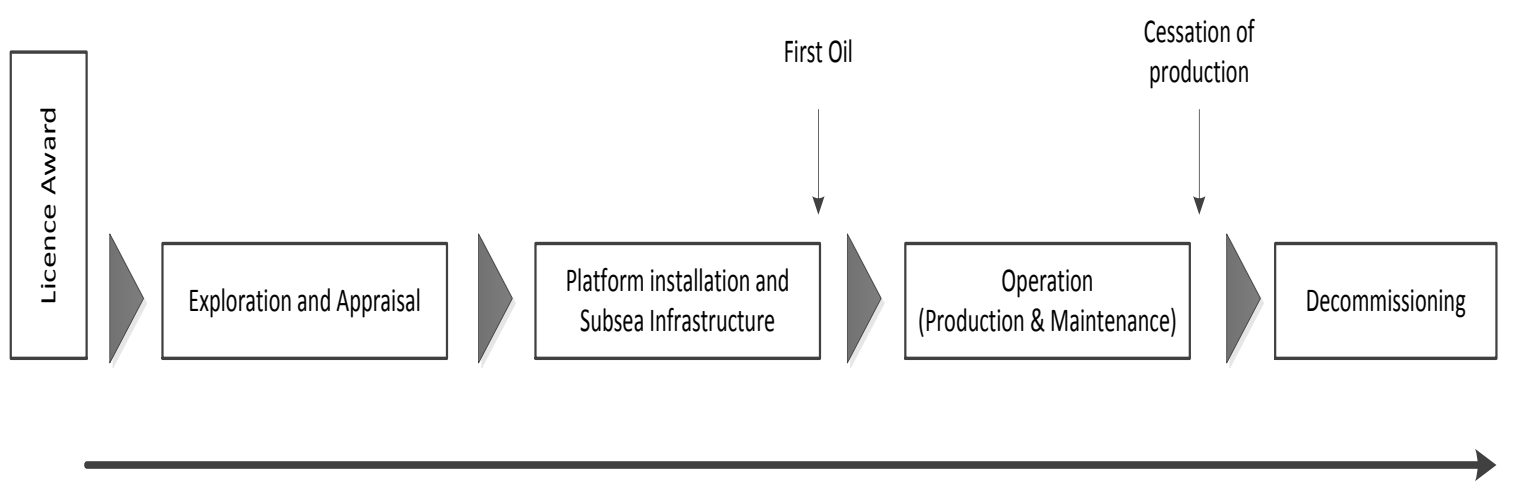


539 Within the current lower-for-longer oil price environment, many operators are faced with the 540 decision to either cease production in sub-economic fields or extend the life of the assets. The

541 timing for CoP resolves around a complex web of factors that includes current oil price, the

542 age of the asset, availability of technology to extend the life of the asset, lifting cost of

543 hydrocarbons, inflation and tax region. As decommissioning is cost intensive, there is also the

544 added disincentive to operators to actually carry out this process in an attempt to delay

545 expenditure for as long as possible. The corollary of the above factors is that the supply chain,

546 mainly contractors and service companies, do not become engaged in the decommissioning

547 process. This point with identified with a contractor stating:

548

549

550

551

'If operators engage us early enough and commit to definite CoP timelines, we would be more than happy to work with them to develop the necessary technology to execute decommissioning projects in a safe and cost effect manner.'

552

553 Similarly, another large North Sea contractor stated:

554

555

556

'We [contractors] tend to be brought into the process very late on when it is usually too late to develop cost effective solutions with the operators.'

557

558 The contractor further stated:

559

560 'They [contractors] won't invest in some new kit if they can't rely on the market. If the market is vaporware, it disappears all the time they could be left with egg on their face. For me this is the main issue affecting the supply chain, everything else pales into insignificance compared to those' 
565 It also follows that with current decommissioning process, which is generally ad hoc in nature, can lead to service companies hesitating to invest in new technologies as there is no assurance

567 of a continuous workload and therefore reap the benefits from their investment. A Technology

568 Manager of a global project management, engineering and construction firms thus noted:

569

570

571

572

573

574

575

576

577

578

579

580

581 While deferment of decommissioning and continued production to maximize economic

582 hydrocarbon recovery within the North Sea basin is generally desirable, the uncertainties in

583 predicted timings to undertake the works creates difficulties in establishing an effective market

A member of small service company also suggested:

'If oil companies keep putting off a project, contractors are unable to commit and wouldn't risk investing heavily in new equipment without a clear idea as to if or when it will be required.'

584 place for associated services. Contractors, are therefore, restrained from preparing the 585 necessary technical support and workforce for a market that is constantly in a flux. Perhaps, a way forward is for the industry to become more 'intentional' about sharing its plans, so that respective supply chains can prepared and be able to respond more effectively. 
589 Contrary to the prevailing market position, however, ConocoPhillips (UK) Ltd, one of the 590 largest exploration and production companies, has embarked on a 15-year campaign to

591 decommission its gas platforms in the Southern North Sea. The campaign, instead of a one-off 592 project, includes the P\&A of almost 140 offshore wells. It completed 15 well P\&A in a 435 593 day campaign in 2014 (ConocoPhillips, 2015). This long term program outlay provides a 594 guarantee of workload for their contractors and suppliers, allowing them to venture into 595 developing innovative technologies that are being used to reduce costs. The campaign approach 596 also allows for aggregating work over several structures and thus the transfer of knowledge 597 between wells and structures. Unfortunately, most operators in the North Sea do not have such 598 a large portfolio of platforms that need to be decommissioned in order to adopt ConocoPhillips 599 Ltd approach.

600

601

\section{Technical Challenges}

602 A number of technical challenges for P\&A, lifting technology, post-decommissioning 603 monitoring and evaluations, disposal of the offshore waste once brought onshore as well as 604 access and egress to remote installations were identified through the interviews in relation to 605 decommissioning in the North Sea.

606

607

\section{Well Plug and Abandonment}

608 One of the main challenges in the removal of installations relates to P\&A. Hydrocarbon 609 reservoirs can be approximately 2 to $3 \mathrm{~km}$ below the seabed level, so the well that is drilled 610 from the platform to the reservoir creates a route for the oil and gas to flow from beneath the seabed to the platform for processing and separation. At the end of the well's life, this route

612 must be closed up so that remnant hydrocarbons in the reservoir cannot come back to the 613 surface. This is the first stage on the critical path for the entire project as installations. Even 
614 though well P\&A is not new to the industry, it is perhaps the sheer volume of wells and fields

615 that need to be abandoned currently that may present capacity constraints. P\&A currently

616 represents up to $60 \%$ of the entire decommissioning budget (Oil \& Gas UK, 2015a;

617 DecomWorld, 2016).

618

619 Wells can either be co-located with a platform and have been drilled from a permanent 620 installation to which the well is directly connected. They may also be subsea wells that are 621 drilled from a mobile installation and tied back to a local platform. Platform wells may be 622 abandoned using the platform as an operational base. If the original drilling rig is still present, 623 it can be refurbished and reused to abandon the well. However, there were some reservations 624 to this approach mainly due to the cost implications. According Decommissioning Manager of 625 a technology firm noted:

626

627

628

629

630

631

Another interview, a P\&A Manager, indicated that:

632 'Technology needs to be developed to allow the refurbishment of wells without the need to spend vast amounts of money on re-activating drilling rigs.'

635 In addition, platform rigs are in demand for drilling activities and thus there is added 636 competition and constraint for this resource. Furthermore, depending on the age and history of

637 the well and the quality of records, it can be challenging to accurately determine the well state 638 creating risks and uncertainties regarding the appropriate abandonment approach. As noted 
previously, well P\&A can undertaken using platform rigs, mobile rigs mounted on a vessel, or

640 rig-less solutions on a lightweight intervention vessel. The selected approach is dictated by the

641 type and condition of the well. However, the interviews indicated that well conditions are

642 generally poorly documented, thus requiring extensive well integrity surveys to be undertaken

643 to establish their conditions. This however, may not necessarily remove all the uncertainties

644 associated with the well condition as evident in the example below.

645

646 Shell UK's well-engineering team encountered small quantities of gas in higher formations,

647 which required significant modifications to their work plans for plugging the 160 wells in the

648 Brent field. This necessitated an additional intermediate cement barrier across the well to act

649 as a seal to prevent gas migration to the surface. According to Shell UK (2010), steel pipes

650 used during the well construction had to be cut and recovered to the surface before the cement

651 plug could be placed - leading to extensive schedule slippage on their original program.

652

653 Schedule slippages, however, can result in significant cost overrun during offshore works as

654 day-rates for rigs used to complete activities are very high. Semi-submersible rigs, for example

655 could cost as much as US $\$ 400,000$ per day prior to 2015 (North Sea Reporter, 2015). Since the 656 price of oil has significantly dropped such rigs can be hired for as little as US\$200,000 per day.

657 Shell's P\&A data demonstrates that on average, it costs $£ 2.7$ million per well for the Brent 658 decommissioning project with the time to safely complete this activity being approximately 30

659 days. Based on these figures, it could take over 13 years to P\&A all the 160 wells in the Brent 660 field at a total cost of $£ 432$ million, assuming a single crew undertook this work sequentially 661 (Royal Academy of Engineering, (2013).

662 


\section{Lifting Technology}

664 Removal or lifting vessels are a critical part of the decommissioning process and their 665 availability has a substantial impact financial viability of the project. No two platforms are the 666 same - each is designed with specific basic data, with varying reservoir details and subsea

667 conditions. As previously noted there are a number of methods to remove offshore installations, 668 which are explained in detail:

669

670 1. Piece-small - this is the most popular approach in the North Sea at the moment. The installation will normally be dismantled into small sections and transported onshore. The whole operation can take several days and there is a higher exposure to the vagaries of the weather and potential occurrence of health and safety incidents.

674

2. Reverse installation - in this approach, whole modules are removed in the reserve order of installation and loaded onto a barge for transportation back to shore. Significant engineering and inspection is required to ensure the integrity of the module structures and lifting points.

3. Single lift - where the jacket or topside is removed in one piece and transported to an onshore facility for reuse or dismantling. There is the opportunity to save time and cost using single lifters. Technical and engineering input may also be significantly reduced.

681

682 The interview data however indicated that there are resource constraints on the available heavy 683 lift vessels to complete single lifts. The most common decommissioning approaches there are reverse installation or piecemeal method. These approaches are somewhat established and secure, but time-consuming and labor intensive. As noted by the Special Project's Lead for a contracting firm: 
"Piece small is rather labor-intensive with a large offshore team working for long periods of time. The costs quickly add-up in terms of wages. Furthermore, cutting the structure into pieces also removes the potential for reuse of the facility."

691

692 Identifying major platform components for possible reuse on other platforms is a challenge, 693 since much of this equipment was designed decades ago and the specifications and 694 performance will often be deemed inappropriate for modern installations.

695 More often than not deepwater structures are floated in place and not lifted with a crane-barge. 696 Thus, most of these have to be reverse installed during the removal - increasing the cost and 697 time associated with completing their decommissioning. Single lift vessels can complete lifts 698 faster, and therefore significantly lower offshore costs, but their availability is a major 699 constraint as these same vessels are used around the world and in other markets such as the 700 wind energy sector. The capital costs of developing new vessels are generally prohibitive. 701 Vessel operators will thus require a substantial commitment to invest in new capacity.

Allseas, however, recently completed the development of the Pioneering Spirit, a twin-bow vessel which is $382 \mathrm{~m}$ long and $124 \mathrm{~m}$ wide and designed for pipe-lay projects as well as decommissioning (Allseas, 2016). The vessel has the ability to lift, store and transport both the topside and jacket of a structure, which could prove to be revolutionary in the progression of the decommissioning sector. It has topside and jacket lift capacities of 48,000 tonnes and 25,000 tonnes respectively. Its sheer size and onboard technology means that it can better withstand adverse weather conditions in the North Sea and therefore could potentially reduce

710 project completion time and associated costs. The Pioneering Spirit will commence offshore operations in the summer of 2016 with removal of the Yme topsides in the Norwegian North 
712 Sea before removing the 24,000 tonne topside of the Brent Delta platform in the 2017 (Shell

713 U.K, 2015 ; Allseas, 2016). Yet, the vessel was primarily built for offshore pipe-laying around

714 the world. The potential challenge with the use of the Pioneering Spirit, however, is that of 715 availability, as pointed out by the Decommissioning Manager of an operator:

"The current lead times for the vessel are about 3 years because it's one of its kind. Once it leaves the North Sea, it will be very expensive to get them back as you'll have to pay for the mobilization to get it back so there will be a significantly higher cost to get it back in the North Sea"

721

\section{Conclusions}

723 A significant number of offshore installations in the North Sea have either exceeded or 724 are approaching the end of their designed economic life span and have to be 725 decommissioned to meet the stringent regulatory framework that has been established.

726 The fledgling decommissioning sector in the North Sea faces a number of challenges that

727 need to be addressed in order to decommission offshore assets in a safe, cost effective 728 and environmentally responsible manner. This paper presents some of the key challenges 729 that were identified through semi-structured interviews with industry professionals operating in the North Sea basin.

731

732 Anecdotal data suggests that a significant number of decommissioning projects exceeded 733 their initial budgets to the tune of about $40 \%$. This is mainly due to a number of factors 734 including the lack of portfolio experience in undertaking or planning for 735 decommissioning projects, unavailability of benchmark figures as well as the structural, technical, temporal and directional complexities associated with removing aged offshore 
assets from high risk environments in the North Sea. It is recommended that industrywide decommissioning knowledge and information sharing be encouraged and facilitated to support cost benchmarking during the planning phase of the decommissioning process. The availability and costs associated with heavy-lift vessels was also identified as a

741 potential challenge to performing single-lift removals instead of the traditional labour intensive piece small method. The uncertainties regarding the timing of decommissioning works create difficulties in establishing an effective market place for services. This was found to be limiting the drive to invest in innovative cost saving technologies for decommissioning.

747 Plug and abandonment works contribute up to $60 \%$ of the decommissioning budget. Yet, completing a safe and secure well abandonment is fraught with a number of challenges including the uncertainties relating to well integrity and the fact that each well is unique 750 - they must thus be approached on a case by case basis making the planning for resources,

751 scheduling and costing rather challenge. The problem is exacerbated by the poorly

752 documented well conditions over the last 30 to 40years. Furthermore, a considerable 753 amount of installations, particularly those installed before the 1998 OSPAR regulations, were not designed from the outset for full removal in mind. As a result this adversely impacts the costs associated with decommissioning particularly as the installations must be removed at the end of its life, with the exception of cases where derogation has been granted.

Knowledge capture and transfer has been powerfully utilized in other aspects of the exploration and production within the oil and gas industry. This, however, tends to be contained within the same organization due to market competition. The challenges facing 
the industry, with regard to decommissioning, necessitate a different mindset and approach to knowledge sharing and collaboration, particularly in relation to process and lessons learnt. In addition, operators need to become more 'intentional' about sharing their plans so that the supply chain can better prepare and respond more effectively. Operators may also need to move from the ad hoc and opportunistic abandonment to a campaign-approach to become more cost-effective. The lessons learnt so far indicate that it will be expedient to adopt a design for decommissioning mentality for future installations. This will hopefully allow for appropriate removal methods to be considered from the outset so as to reduce the significant decommissioning expenditure as well make the works safer to undertake.

Decommissioning is complex, capital intensive and is carried out in high-risk environments offshore. The North Sea based firms, however, have the opportunity to become global leaders in the safe and cost-effective decommissioning of offshore installations. This expertise can later be exported to other basins like the Gulf of Mexico, South China Sea, West Africa and the Northwest Shelf in Australia. Significant work is required to address the capacity and skills capability limitations that currently exist within the supply chain. This exploratory research provides the impetus for future research in this fertile and emerging field.

\section{Future Research}

Future research should explore the development of reliable cost models that perhaps combines aspects of expert systems, probabilistic theory and case-based reasoning due to the unique nature and complexity of each decommissioning project. There is also scope to employ a systems dynamic approach within the context of structured-case studies to 
796

797

798

799

800

801

802

803

804

805

806

807

808

809

810

811

812

813

model the nature of complexities and their impact on cost, time and safety when planning and executing decommissioning projects.

Another potential direction for future research could be in the use of remote visualization technologies to help in the scoping and familiarization of the offshore installations at the planning stage as well as the development of retrospective as-built digital representation for facilities that do not have up-to-date or existing as-built to support asset integrity assessments in relation to appropriate decommissioning alternatives.

\section{References}

Allseas. (2016). Pioneering Spirit. URL: http://allseas.com/equipment/pioneering-spirit/ [March 2016]. Allseas

Bell, N. \& Smith, J. (1999). Coral growing on North Sea oil rigs. Nature, 402, 601-601.

Bennie, L. G. (1998). Brent Spar, Atlantic Oil and Greenpeace. Parliamentary Affairs, 51, 397410.

Bernstein, B., Bressler, A., Cantle, P., Henrion, M., John, D., Kruse, S., Pondella, D., Scholz, A., Setnicka, T. \& Swamy, S. (2010). Evaluating alternatives for decommissioning California's oil and gas platforms: A technical analysis to inform state policy. California Ocean Science Trust. calost. org/scienceinitiatives.

ConocoPhillips. (2015). ConocoPhillips tackle the unique challenges of decommissioning in a mature basin in a cost competitive environment. URL: http://bit.ly/29fDa3G [02/07/2016]. Oil and Gas, UK

DECC (2011). Guidance Notes - Decommissioning of Offshore Oil and Gas Installations and Pipelines under the Petroleum Act 1998. Version 6 ed. Aberdeen, UK: Offshore Decommissioning Unit, Department of Energy and Climate Change (DECC).

DECC (2014). UK Energy in Brief. Department of Energy and Climate Change.

DecomWorld (2016). North Sea Late Life Strategy Survey Results 2016. FCBI Energy Ltd®: DecomWorld.

Dickie, I. \& Howard, N. (2000). Assessing environmental impacts of construction: Industry consensus, BREEAM and UK Ecopoints. Watford: Building Research Establishment 
Ekins, P., Vanner, R. \& Firebrace, J. (2006). Decommissioning of offshore oil and gas facilities: A comparative assessment of different scenarios. Journal of Environmental Management, 79, 420-438.

Fowler, A. M., Macreadie, P. I., Jones, D. O. B. \& Booth, D. J. (2014). A multi-criteria decision approach to decommissioning of offshore oil and gas infrastructure. Ocean \& Coastal Management, 87, 20-29.

Genesis and DECC. (2015). The real costs of decommissioning. URL: http://decomnorthsea.com/news/the-real-costs-ofdecommissioning [12-05-16]. Decom North Sea

Hamilton, A. (1997). Management by Projects - achieving success in a changing world. London: Thomas Telford Services Ltd.

Hamzah, B. A. (2003). International rules on decommissioning of offshore installations: some observations. Marine Policy, 27, 339-348.

HMRC (2016). Statistics of Government revenues from UK oil and gas production. May 2016 ed. London, UK: Her Majesty's Revenue and Customs.

Kaiser, M. J. \& Liu, M. (2014). Decommissioning cost estimation in the deepwater U.S. Gulf of Mexico - Fixed platforms and compliant towers. Marine Structures, 37, 1-32.

Little, J., Fleming, C., Donnelly, B. \& Ltd., R. T. S. (2016). Using a Forensic Tool to Save Bed Space With Visual Planning. In: Society of Petroleum Engineers Conference, 2016 of Conference Aberdeen, UK. Society of Petroleum Engineers, SPE-181045-MS.

Löfstedt, R. E. \& Renn, O. (1997). The Brent Spar controversy: an example of risk communication gone wrong. Risk Analysis, 17, 131-136.

Love, M. S., Schroeder, D. M., Lenarz, W., MacCall, A., Bull, A. S. \& Thorsteinson, L. (2006). Potential use of offshore marine structures in rebuilding an overfished rockfish species, bocaccio (Sebastes paucispinis). Fishery Bulletin, 104, 383-390.

Macreadie, P. I., Fowler, A. M. \& Booth, D. J. (2011). Rigs- to- reefs: will the deep sea benefit from artificial habitat? Frontiers in Ecology and the Environment, 9, 455-461.

Macreadie, P. I., Fowler, A. M. \& Booth, D. J. (2012). Rigs- to- reefs policy: can science trump public sentiment? Frontiers in Ecology and the Environment, 10, 179-180.

Manning, D. (2015). Cell Sampling Update, Brent Delta Decommissioning (December 2015). URL: https://goo.gl/6mBS4W [17th October 2016]. Shell, UK

North Sea Reporter (2015). North Sea Rig Markets. In: KL Energy Publishing Limited (ed.). http://www.klenergypublishing.com. 
850

851

852

853

854

855

856

857

858

859

860

861

862

863

864

865

866

867

868

869

870

871

872

873

874

875

876

877

878

879

880

881

882

OGA. (2016). Oil and gas: infrastructure. URL: http://www.gov.uk/guidance/oil-and-gasinfrastructure [Feb 2016]. Oil and Gas Authority

Oil \& Gas UK (2013). Activity Survey 2013. London \& Aberdeen: Oil and Gas UK.

Oil \& Gas UK (2014a). Activity Survey 2014. London \& Aberdeen: Oil and Gas UK.

Oil \& Gas UK (2014b). Decommissioning Insight 2014. London \& Aberdeen: Oil and Gas UK.

Oil \& Gas UK (2015a). Activity Survey 2015. London \& Aberdeen: Oil and Gas UK.

Oil \& Gas UK. (2015b). Key Facts about the UK Oil and Gas Industry. [March 9th 2016]. Oil and Gas UK,

OSPAR (1999). OSPAR Decision 98/3 on the Disposal of Disused Offshore Installations. Ministerial Meeting of the OSPAR Commission. Sintra: OSPAR Convention for the Protection of the Marine Environment of the North-East Atlantic.

OSPAR (2015). Inventory of Offshore Installations. In: OSPAR Commission (ed.) Publication 656. London, http://www.ospar.org.

OSPAR. (2016). Offshore Installations. URL: http://www.ospar.org/workareas/oic/installations [Feb 2016]. OSPAR Commission

Parente, V., Ferreira, D., Moutinho dos Santos, E. \& Luczynski, E. (2006). Offshore decommissioning issues: Deductibility and transferability. Energy Policy, 34, 19922001.

Patton, M. Q. (2001). Qualitative research \& evaluation methods. 3rd ed. Saint Paul, MN: Sage Publications.

RAE (2013). Decommissioning in the North Sea - A report of a workshop held to discuss the decommissioning of oil and gas platforms in the North Sea. In: Jamieson, A. (ed.). London: Royal Academy of Engineering.

Remington, K. \& Pollack, J. (2007). Tools for complex projects. Gower Publishing, Ltd.

Rini, N., Kurian, V., Liew, M. \& Whyte, A. (2016a). Coupled analysis effected by wave height on FPSO motions. In: Zawawi (ed.) Engineering Challenges for a Sustainable Future. CRC Press /Taylor Francis Group.

Rini, N., V.J, K. \& Whyte, A. (2016b). Dynamic Behaviour of FPSOs in the Kikeh-Field under Different Loading Conditions. ARPN Journal of Engineering and Applied Science, 11(4), 2302-2307.

Shell U.K (2010). Decommissioning the Brent Field - Brent E-news. Shell U.K. Limited.

Shell U.K (2015 ). Decommissioning the Brent Field. Shell U.K. Limited. 
883 Thomas, J. B., Clark, S. M. \& Gioia, D. A. (1993). Strategic sensemaking and organizational

884

885

886

887

888

889

890

891

892

893

894

895

896

897 performance: Linkages among scanning, interpretation, action, and outcomes. Academy of management journal, 36, 239-270.

Von Bertalanffy, L. (1956). General system theory. General systems, 1, 11-17.

Whyte, A., Dyer, T. \& Dhir, R. (2005). Best Practicable Environmental Options (BPEOs) for Recycling Demolition Waste. In: Dhir, R., Dyer, T. \& Newlands, M. (eds.) Achieving Sustainability in Construction. London: Thomas Telford Publishing.

Whyte, A. \& Laing, R. (2012). Deconstruction and Reuse of Building Material, with Specific Reference to Historic Structures. In: al, V. e. (ed.) Research, Dev. \& Practice in Structural Engineering \& Construction.

Wilkinson, W., Bakke, T., Clauss, G., Clements, R., Dover, W., Rullkötter, J. \& Shepherd, J. (2016). Decommissioning of large offshore structures-The role of an Independent Review Group (IRG). Ocean Engineering, 113, 11-17. 